\title{
Performance Analysis of Permanent Magnet Synchronous Machine due to Winding Failures
}

\author{
Sandhya Kulkarni ${ }^{1}$ and Dr. Archana Thosar ${ }^{2}$ \\ IDepartment of Electrical Engineering, Govt. College of Engineering, Aurangabad, (M.S.), India., sskulkarni @ geca.ac.in \\ ${ }^{2}$ Department of Electrical Engineering, College of Engineering, Pune (M.S.) India, archanagthosar@ gmail.com
}

*Correspondence: Sandhya Kulkarni; Email: $\underline{\text { sskulkarni@geca.ac.in }}$

\begin{abstract}
The paper describes winding failures in Permanent Magnet Synchronous Motor (PMSM) which are preferred in Electric Vehicles. Drive can be designed with fault tolerance to continue to operate under occurrence of faults. Winding insulation failure is responsible for some of the most serious faults. A method for detecting open circuit of winding, short circuit of winding or turn to turn short circuit in winding may result as a failure of winding insulation is presented. Further a technique for continued post-fault operation of the drive is discussed based upon mathematical model. The detection method operates in real time without the use of additional sensors and is sensitive enough to detect the presence of an air-gap between turns.
\end{abstract}

Keywords: Fault Tolerance, Open circuit of winding, PMSM, Short circuit of winding, Winding Failure

\section{ARTICLE INFORMATION \\ Author(s): Sandhya Kulkarni and Dr. Archana Thosar \\ Received: Nov 22, 2021; Accepted: Jan 05, 2022; Published: Jan 30, 2022; e-ISSN: 2347-470X; \\ Paper Id: IJEER-090308; \\ Citation: doi.org/10.37391/IJEER.090308 \\ Webpage-link: \\ https://ijeer.forexjournal.co.in/archive/volume-9/ijeer-090308.html}

\section{INTRODUCTION}

Fault tolerant drive has become essential many critical applications. Many researchers have contributed on fault tolerant operation of PMSM. Some authors have indicated that PMSM are better suited especially in electric vehicles and aerospace [1]. A novel PMSM design has been shown to be capable of continued operation in presence of winding failures causing short circuit of phases or short circuit at terminals [2]. The reconfiguration of the power converter allows for continuous operation of a power device either for an open circuit fault or even failure of a power device due to a short circuit. Failures occurring within one or more machine phases due to the breakdown of winding insulation are one possible failure that has not been adequately covered to date. These faults are most among all other types of faults. Hence the effects of winding failures are discussed in this paper. Electric motors are exposed to the adverse conditions of heat and vibrations. This may cause the progressive deterioration and eventual failure of stator winding insulation which is a major cause of failure of motor [4]. Winding insulation failure in machine may led to turn to turn short circuit of winding, phase to phase fault or may cause air-gap separation among phases causing phase to ground fault or led to open circuit fault. Much work exits on the causes and effects of shorted turns in machine windings [5-7]. Some work has been done to develop techniques for detecting shorted turns. Most of these techniques may be classified as flux based and or current based or using finite element [8-9]. A variety of offline diagnostic techniques for shorted turns in super conducting magnet is described [10]. But till date it is observed that none of work is able to provide a simple detection technique without need of additional sensors to monitor and detect fault. Organization of paper is done as: The mathematical model used to detect faults is described in Section II while Section 3 discusses the methodology for fault diagnosis and the mathematical model under fault. Section 4 discusses the development of a magnetic model to analyze winding failures. Section V discusses simulation results, and Section VI provides conclusions.

\section{DEVELOPMENT OF MATHEMATICAL MODEL}

Permanent magnets generate air-gap magnetic flux in the PMSM. These machines offer a high torque density as well as a broad operating range. Based on the direction of field flux, these motors are classified into two types [11-12]. It is referred to as a radial flux PMSM. If the direction of flux, is along the radius of the machine, and an axial flux PMSM if the flux direction is parallel to the rotor shaft. PMSMs are also classified based on the position of magnets on the rotor [13]. If the magnets are placed on the rotor's outer surface, the motor is known as a Surface Mounted PMSM (SPMSM). If the magnets are placed in the center of the rotor laminations, the motor is referred to as an interior PMSM (IPMSM). The different configurations of PMSM are depending on placement of magnets as shown in Fig.1. In SPMSMs, magnets are in direct contact with the air-gap. This gives the highest air-gap flux density and are suitable for speed range up-to $1800 \mathrm{rpm}$ hence are widely preferred for various applications [14-15]. IPMSMs have magnets buried inside the rotor. So, these machines more suitable for high-speed and extremely fast applications, but are difficult to manufacture. The rotor magnet field axis is represented by the d-axis. The q-axis is $90^{\circ}$ electrical from the d-axis and flux path is through the iron laminations. The different configurations of each rotor type are shown in Figure1. 


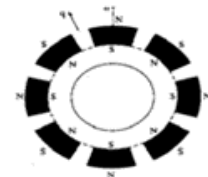

a) SPMSM

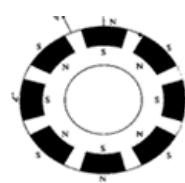

b) SIPMSM

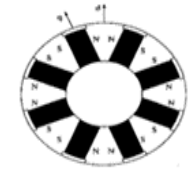

c) IPMSM
Figure 1: Different configurations of PMSM based on the magnet placement

This paper focuses on a balanced three-phase SPMSM with star connected stator winding, which is one of the most common PMSM configurations. The stator voltages in the stator frame of reference for a balanced three phase PMSM (also known as the abc frame of reference), is given by equations (1)-(3).

$$
\begin{aligned}
& V_{a}=R_{a} L_{a}+L_{a} \frac{d i_{a}}{d t} M_{a b} \frac{d i_{b}}{d t}+M_{a c} \frac{d i_{c}}{d t} \\
& V_{b}=R_{b} L_{b}+L_{b} \frac{d i_{b}}{d t}+M_{a b} \frac{d i_{a}}{d t}+M_{b c} \frac{d i_{c}}{d t} \\
& V_{c}=R_{c} L_{c}+L_{c} \frac{d_{c}}{d t} M_{a c} \frac{d i_{a}}{d t}+M_{b c} \frac{d i_{b}}{d t}
\end{aligned}
$$

Here $V_{a}, V_{b}$, and $V_{c}$ represents the three-phase voltages of stator and $i_{a}, i_{b}$, and $i_{c}$ are three phase stator currents. Equation (4) to (6) represents stator flux linkages.

$$
\begin{aligned}
& \lambda_{\mathrm{a}}=\lambda_{\mathrm{pm}} \sin (\theta) \\
& \lambda_{\mathrm{b}}=\lambda_{\mathrm{pm}} \sin \left(\theta-120^{\circ}\right) \\
& \lambda_{\mathrm{c}}=\lambda_{\mathrm{pm}} \sin \left(\theta+120^{\circ}\right)
\end{aligned}
$$

Park's transformation is used to simplify the mathematical model by converting the stator three phase $a b c$-frame to the two-phase rotating $d q$ rotor reference frame. This transformation is applied in two stages. First, using Clark's transformation, the stator three phase quantities given by equations (1) to (3) are transformed to the equivalent stationary frame where $(\theta)$ denotes the rotor position.

$\left[\begin{array}{l}\mathrm{i}_{\mathrm{d}} \\ \mathrm{i}_{\mathrm{q}} \\ \mathrm{i}_{0}\end{array}\right]=\frac{2}{3}\left[\begin{array}{ccc}\cos \theta & \cos \left(\theta-\frac{2 \pi}{3}\right) & \cos \left(\theta+\frac{2 \pi}{3}\right) \\ -\sin \theta & -\sin \left(\theta-\frac{2 \pi}{3}\right) & -\sin \left(\theta+\frac{2 \pi}{3}\right) \\ -\frac{1}{2} & -\frac{1}{2} & -\frac{1}{2}\end{array}\right]\left[\begin{array}{c}\mathrm{i}_{\mathrm{a}} \\ \mathrm{i}_{\mathrm{b}} \\ \mathrm{i}_{\mathrm{c}}\end{array}\right]$

It should be noted that this transformation is invertible; the Park's inverse transformation matrix used to transform the mathematical machine model from the dq frame of reference to the abc frame of reference as follows:

$$
\begin{gathered}
\mathrm{I}_{\mathrm{dq}}=\mathrm{PI}_{\mathrm{abc}} \\
\mathrm{I}_{\mathrm{abc}}=\mathrm{P}_{\mathrm{inv}} * \mathrm{I}_{\mathrm{dq}}(9) \\
{\left[\begin{array}{l}
\mathrm{i}_{\mathrm{a}} \\
\mathrm{i}_{\mathrm{b}} \\
\mathrm{i}_{\mathrm{c}}
\end{array}\right]=\frac{1}{3}\left[\begin{array}{ccc}
\cos (\theta) & -\sin (\theta) & 1 \\
\cos \left(\theta-\frac{2 \pi}{3}\right) & -\sin \left(\theta-\frac{2 \pi}{3}\right) & 1 \\
\cos \left(\theta+\frac{2 \pi}{3}\right) & -\sin \left(\theta+\frac{2 \pi}{3}\right) & 1
\end{array}\right]\left[\begin{array}{c}
\mathrm{i}_{\mathrm{d}} \\
\mathrm{i}_{\mathrm{q}} \\
\mathrm{i}_{0}
\end{array}\right]}
\end{gathered}
$$

Where $\mathrm{P}_{\text {inv }}$ is the inverse of Park's transformation matrix.

Equation (7) is the PMSM model in the two-phase rotating frame. By use of the transformation matrix of equation (9) results in equation (10). Rotor angle position $(\theta)$ can be measured with a rotor position sensor or estimated. When the motor rotates at synchronous speed, the dq quantities in the rotor frame of reference become stationary quantities whose vector diagram and equivalent circuit of transformation is shown in Fig. 2
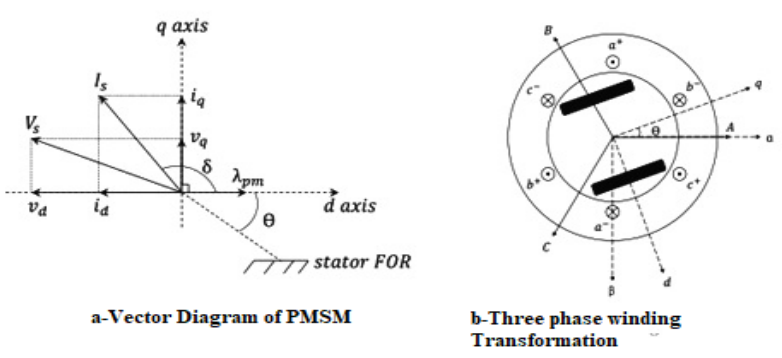

Figure 2: Simplified model of PMSM with vector diagram and transformation

Let $\mathrm{Vd}, \mathrm{Vq}$, id, iq be the voltages and currents in dq- frame. Rs is a stator resistance, $\boldsymbol{\Psi}_{\mathrm{d}}, \boldsymbol{\Psi}_{\mathrm{q}}$ are flux linkages, $\mathrm{Ld}$ and $\mathrm{Lq}$ are inductances in $\mathrm{dq}$ frame. Magnet flux linkage is represented by $\boldsymbol{\Psi}_{\mathrm{m}}$. During steady-state operation of motor, the motor rotates at a constant speed and torque, the $\mathrm{dq}$ quantities are converted to DC quantities. Hence, the time varying components $\frac{\mathrm{di}_{\mathrm{d}}}{\mathrm{dt}}$ and $\frac{\mathrm{di}_{\mathrm{q}}}{\mathrm{dt}}$ will be zero. Thus equation (11) to (13) represents the mathematical model of PMSM at steady-state in dq frame.

$$
\begin{aligned}
& \mathrm{V}_{\mathrm{d}}=\mathrm{R}_{\mathrm{s}} \mathrm{i}_{\mathrm{d}}-\Psi_{\mathrm{q}} \mathrm{i}_{\mathrm{q}} \\
& \mathrm{V}_{\mathrm{q}}=\mathrm{R}_{\mathrm{s}} \mathrm{i}_{\mathrm{q}}+\Psi_{\mathrm{d}} \mathrm{i}_{\mathrm{d}} \\
& \mathrm{T}=\frac{3 \mathrm{P}}{2}\left(\Psi_{\mathrm{d}} \mathrm{i}_{\mathrm{q}}-\Psi_{\mathrm{q}} \mathrm{i}_{\mathrm{d}}\right)
\end{aligned}
$$

Torque is generated by the interaction of the flux linkages and the current in each axis. Fig. 2 depicts a more accurate representation of the mathematical machine model [16]. The flux linkage due to the magnets $\boldsymbol{\Psi}_{\mathrm{m}}$ is along the d-axis and the $\mathrm{q}$-axis is in quadrature with that of $\mathrm{d}$-axis. As the q axis current is perpendicular to the magnet flux $\boldsymbol{\Psi}_{\mathrm{m}}$, it generates the majority of the torque, while id is used to control the amount of flux [17]. So, generated torque is controlled by adjusting the stator current magnitude (Is) and rotor angle $(\theta)$. It should be noted that this model assumes that the stator resistance and self-inductance are the same for all three phases (i.e. $\mathrm{Ra}=\mathrm{Rb}$ $=\mathrm{Rc}=\mathrm{Rs}, \mathrm{La}=\mathrm{Lb}=\mathrm{Lc}$ ). This model also ignores iron losses, as well as self and cross saturation between the stator's three phases. However, it accurately represents the machine's basic characteristics and performance. It should be noted that the proposed method is also applicable to all types of PMSM [18]. Hence, this model will serve as the reference machine model. The mathematical model under normal conditions must be 
modified to work under fault conditions. Under normal conditions, three phases are balanced, resulting in balanced winding resistances and reactance. However, failures in windings may occur during motor operation due to open circuit of windings, windings shorting of turns in one or more phases. The following section discusses the methodology of fault diagnosis in the machine for various faults [19].

\section{METHODOLOGY OF FAULT DIAGNOSIS}

Fault diagnosis techniques are classified as software based and hardware based. Hardware based techniques use different approaches such as redundant switch, redundant leg, matrix converter, phase redundant topology, cascade converter etc. to achieve fault tolerant control. But these methods are less preferable, as they require complicated hardware and high operation cost. Hence, fault tolerant control using software with low-cost reconfiguration is usually preferred. Software based techniques are model based. Proposed technique is model based, requiring mathematical equations and physical parameters or data driven. Mathematical model in previous section has given factors which controls state variables under healthy condition.

\subsection{Development of Mathematical Model for Faulty Condition}

Step 1: The substation metered load profiles data are mined for two features (1) data density and (2) feature and shape extraction which uses normalization for shape data only. Substations are grouped as per the TLP's shape, producing load cluster images using various iterative algorithms. An average normalized template, load shape of TLP within load group, to represent the overall load profile shape from the substations metered data with each cluster for metered over days.

Step 2: The relationship between fixed retrieved data and these developed clusters of substations is characterized. A classification method uses the multinomial Logical Regression model. It can mark on the HOG plot undetected substations metered data to each cluster with a probability completely based on the fixed data. This is imitable by time periods and unknown areas, for which real-time metered load (KW) data.

Step 3: The normalized vectors will be scaled up by suitable Eigen value to load magnitude density distribution vectors and shape vectors. For unmonitored substations, the actual scaling process is sometimes used to estimate peak loads distribution as bright spots in the images meant for feature extraction.

\subsection{Faulty Condition- fault on Phase ' $a$ '}

In the event of phase fault shown in Figure 3, $d q$ axis current is immediately distorted.

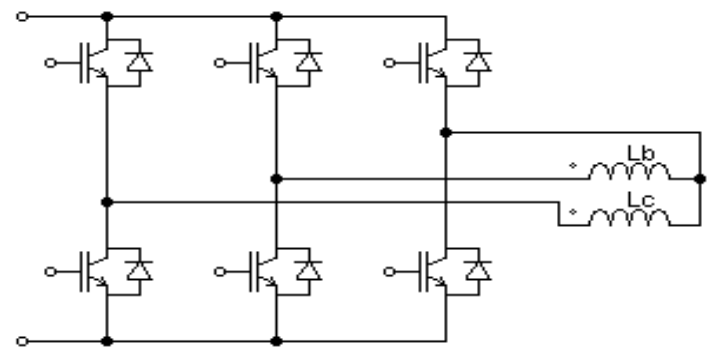

Figure 3: Circuit diagram showing fault on phase ' $a$ '

As seen from the above formula and by ensuring that the resultant torque remains same before and after the fault. After occurrence of fault on phase ' $a$ ', adjustment of magnitude and phase is required for magnitude and phase of remaining ' $b$ ' and ' $c$ ' phases. This usually is $\sqrt{3}$ times normal phase current and angle is $\pi / 6$ lagging and leading respectively. Magnitude of neutral current is thrice the current as that of current under balanced steady state. Thus, transformed equivalent linear current in rotating two phase $d q$-system is to be obtained. From this, voltage to compensate for torque ripple caused by phase failure is required to be calculated and the error voltage arising is chosen at sampling time $t_{i}$, as sum of the squared errors between predicted values of $\mathrm{d}$-axis and q- axis currents and their corresponding values are expressed in equation (18) and electromagnetic torque expression of PMSM in $d q$-system by equation (19).

$$
\begin{aligned}
& \mathrm{E}=\left(\mathrm{i}_{\mathrm{d}(\mathrm{ti})}-\mathrm{i}_{\mathrm{d}(\mathrm{t}+1)}\right)^{2}+\left(\mathrm{i}_{\mathrm{q}(\mathrm{ti})}-\mathrm{i}_{\mathrm{q}(\mathrm{t}+1)}\right)^{2} \\
& \mathrm{~T}_{\mathrm{e}}=\frac{3}{2} \mathrm{p}\left[\Psi_{\mathrm{m}} \mathrm{i}_{\mathrm{q}}+\mathrm{i}_{\mathrm{d}} \mathrm{i}_{\mathrm{q}}\left(\mathrm{L}_{\mathrm{d}}-\mathrm{L}_{\mathrm{q}}\right)\right]
\end{aligned}
$$

Where $p$ is the number of motor pole pair and $i_{d}, i_{q}$ are transformed stator currents in $d q$-2-phase rotating system. Assuming $L_{d}=L_{q}$ gives electromagnetic torque expressed in equation (18) will be expressed by equation (19).

$$
\mathrm{T}_{\mathrm{e}}=\frac{3}{2} \mathrm{p} \Psi_{\mathrm{m}} \mathrm{i}_{\mathrm{q}}
$$

This shows that torque of motor is proportional to quadrature axis current $i_{q}$. When motor is running without fault, current in $d q$ system is expressed by equation (14) having zero magnitudes of direct axis and zero sequence current leading to whole current of quadrature axis only. But when motor has a phase fault, here on phase $A$ Io is not zero, but is given by$i_{d}=0, i_{q}=-I_{m}, \mathrm{I}_{0}=-I_{m} \sin (\theta)$. So, to achieve constant torque after the phase failure, it is necessary to maintain $d$-axis and $q$ axis currents of rotating system. This is because the change of $\mathrm{i}_{0}$ current keeps the $d$-axis, $q$-axis currents unchanged. This needs change in zero axes current. Equation (21) expresses the zero-sequence voltage after phase failure.

$$
\mathrm{V}_{0}=\mathrm{R}_{\mathrm{s}} \mathrm{i}_{0}+\mathrm{L}_{0} \frac{\mathrm{di}_{0}}{\mathrm{dt}}
$$

Combining equation (5) and (9) the modified resultant voltage, $\mathrm{V} 0$ is expressed by equation (21) 
$V_{0}=\left(R_{s} i_{q}+\Psi_{d} i_{d}\right) \sin \theta+\left(-R_{s} i_{d}+\Psi_{q} i_{q}\right) \cos \theta$

Thus, it can be seen from equation (22) that the voltage $\mathrm{V}_{0}$ is a function of direct axis current id, quadrature axis current iq. and speed. So, the control of voltage $\mathrm{V}_{0}$ is actually the control of id and iq. The equations for flux linkages assumed are expressed as:

$$
\begin{aligned}
& \Psi_{\mathrm{d}}=\mathrm{L}_{\mathrm{d}} \mathrm{i}_{\mathrm{d}}+\Psi_{\mathrm{p}} \\
& \Psi_{\mathrm{q}}=\mathrm{L}_{\mathrm{q}} \mathrm{i}_{\mathrm{q}}
\end{aligned}
$$

Hence simplified equations for torque and $\mathrm{d}-\mathrm{q}$ axis voltages are given by equations (25-28).

$$
\begin{aligned}
& \mathrm{T}=\mathrm{N}_{\mathrm{P}}\left(\mathrm{i}_{\mathrm{q}} \Psi_{\mathrm{d}}-\mathrm{i}_{\mathrm{d}} \Psi_{\mathrm{q}}\right) \\
& \mathrm{T}-\mathrm{T}_{\mathrm{L}}=\frac{\mathrm{d} \omega}{\mathrm{dt}} \frac{\mathrm{M}}{\mathrm{N}_{\mathrm{P}}} \\
& \mathrm{V}_{\mathrm{d}}=\mathrm{R}_{\mathrm{s}} \mathrm{i}_{\mathrm{d}}-\Psi_{\mathrm{d}} \mathrm{i}_{\mathrm{q}} \\
& \mathrm{V}_{\mathrm{q}}=\mathrm{R}_{\mathrm{s}} \mathrm{i}_{\mathrm{q}}+\Psi_{\mathrm{q}} \lambda_{\mathrm{d}}
\end{aligned}
$$

This mathematical model is an exact representation of the real physical model of PMSM and helps to analyze variety of faults taking place in motor whose equivalent circuit is shown in Figure 4.
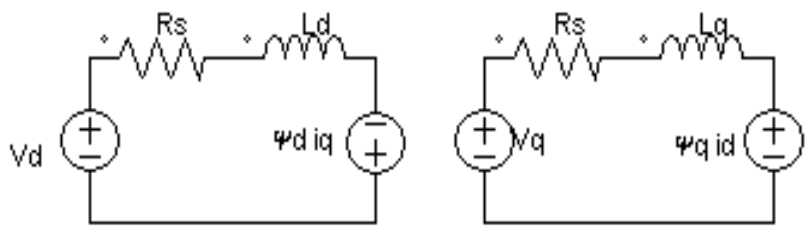

Figure 4: $V_{d}$ and $V_{q}$ equivalent circuit of PMSM in dq-axis model

\section{DEVELOPMENT OF MAGNETIC MODEL}

Mathematical model designed is implemented using MATLAB Simulink-platform. For this magnetic model is developed with total number of 70 slots by considering three teeth per phases as shown in Figure 6 whose parameters are given in Table 1. There are two techniques to execute the program: residual generation and evaluation. The nominal value of residual in a fault-free, healthy system is zero or near to zero. It deviates from zero after occurrence of a fault. Evaluation part determines pattern and residual varying from zero to non-zero. The proposed method uses dynamic model of PMSM in a $d q$ two phase rotating reference frame for detection of open circuit, short circuit, and isolation of turns of windings. It is performed with a residual current vector to estimate the stator currents based on nominal operation of motor as given equation (18), (27) and (28). Detailed structure of magnetic model is shown in Figure 6 for occurrences of faults in 'Tooth No. 1' as windings are open, short circuit of windings ( $50 \%$ considered), grounding of winding and air-gap or isolation between windings. Table 1 show electrical parameters of machine for the proposed system.

Table 1. Parameters of PMSM

\begin{tabular}{|l|l|}
\hline Parameters & Values \\
\hline Rs & $4.3 \Omega$ \\
\hline Ld & $7.5 \mathrm{mH}$ \\
\hline Lq & $7.5 \mathrm{mH}$ \\
\hline Number of poles & 4 \\
\hline DC Voltage & $300 \mathrm{~V}$ \\
\hline Torque & $2 \mathrm{Nm}$ \\
\hline Moment of Inertia & $0.00179 \mathrm{Kgm} 2$ \\
\hline
\end{tabular}

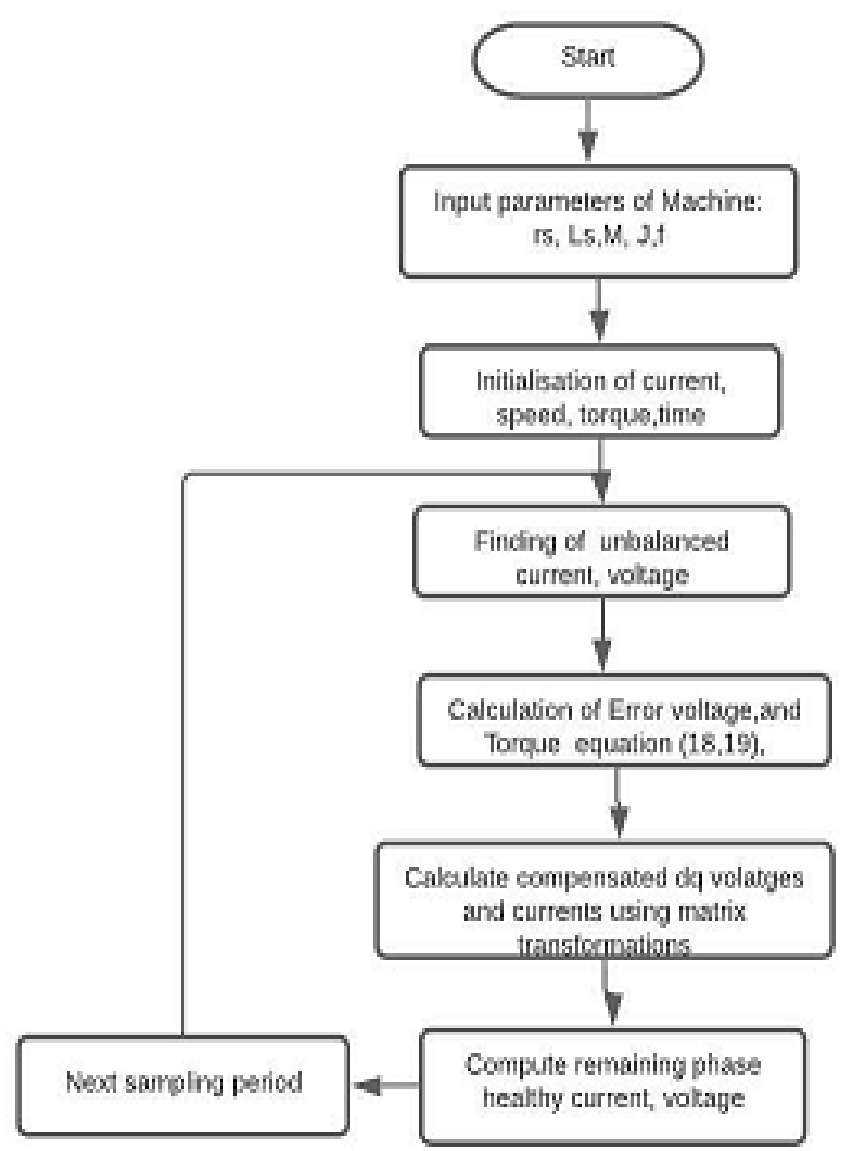

Figure 5: Flow chart for fault detection 


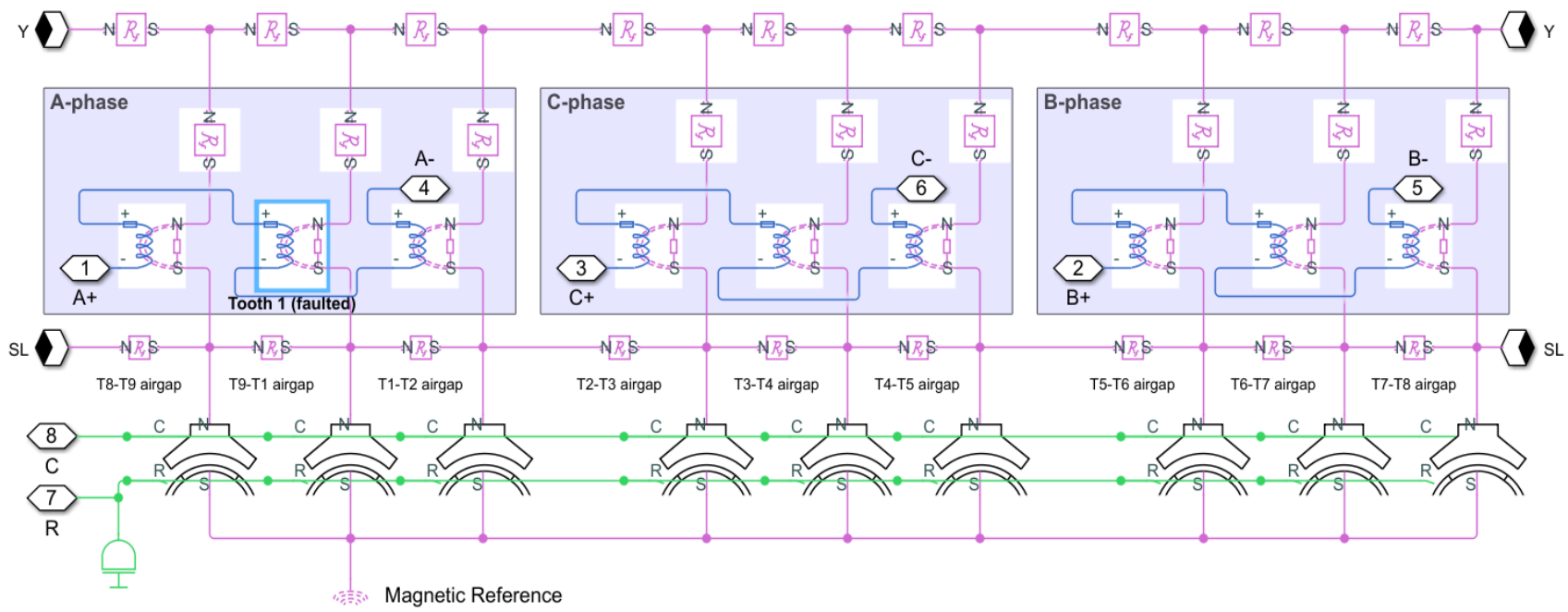

Figure 6: Detailed structure of Implementation of a three phase SPMSM model using MATLAB

\section{RESULTS AND DISCUSSIONS}

Simulation of magnetic model is performed for various operating conditions as discussed below.

\subsection{Normal operation}

Figure $7 a$ shows stator current waveforms of three phases 'A', ' $\mathrm{B}$ ' and ' $\mathrm{C}$ ' and error in Torque is almost zero during fault free operation. Stator currents and flux are synchronous and waveforms for 'mmf' and flux 'phi' are sinusoidal in nature as shown in Figure $7 b$.
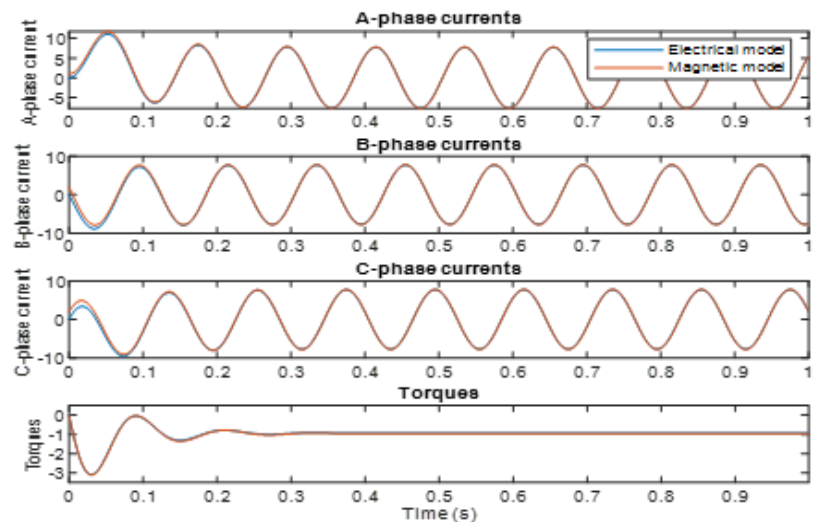

Figure 7 a: Stator currents, torque
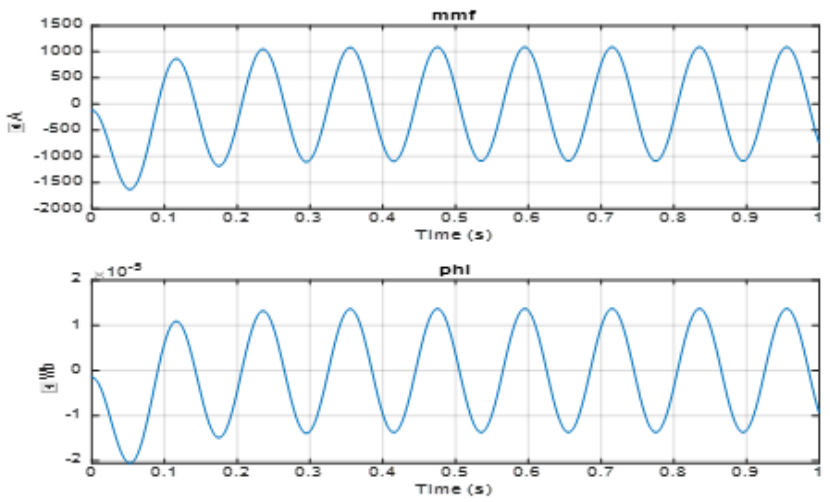

Figure $7 \mathbf{b}$ : Distribution of mmf and flux
5.2 Open-circuit of winding fault in 'Tooth 1' of phase ' $A$ ' As shown in Figure $8 a$, stator current of phase ' $A$ ' is normal from $\mathrm{T}=0$ to $0.4 \mathrm{sec}$, but at $\mathrm{T}=0.4 \mathrm{sec}$, winding of phase ' $\mathrm{A}$ ' is open circuited, this has resulted in its magnetic flux linkage to reduce to zero, but stator current through phase ' $\mathrm{B}$ ' and phase ' $\mathrm{C}$ ' remain unaltered while 'Error' signal of torque is non zero as depicted in Figure $8 a$ from $\mathrm{T}=0.4 \mathrm{sec}$ onwards during open circuit of winding fault. This has affected air-gap flux. This is more clearly observed in 'mmf 'and flux waveform as shown in Figure $8 b$.

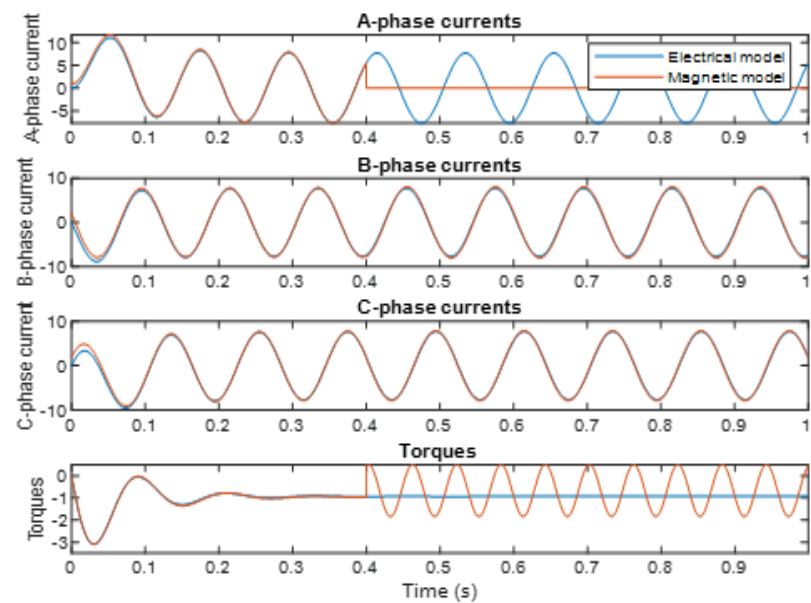

Figure 8 a: Stator currents and torque
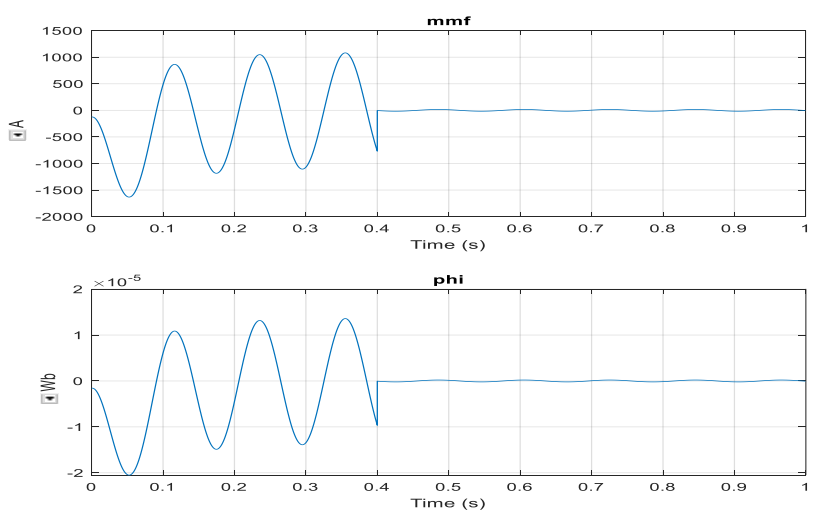

Figure 8 b: Distribution of mmf and flux 
5.3 Short circuit of winding causing phase to Ground fault in 'Tooth 1' of phase ' $A$ '

To observe effect of shorting or grounding of turns of winding, fault is applied at $\mathrm{T}=0.4 \mathrm{sec}$, with $50 \%$ of its turns shorted in 'Tooth 1' of phase 'A'. The simulation waveforms for three phase stator currents as shown in Figure $9 a$ At $\mathrm{T}=0.4 \mathrm{sec}$, phase shift is observed in simulated current of phase ' $A$ ', torque ripple is seen and distorted simulated waveform of 'mmf' and 'flux' is observed as shown in Figure 9b. Normal flux in T4-T5 Tooth (healthy) is seen during same time as shown in Fig. 10.
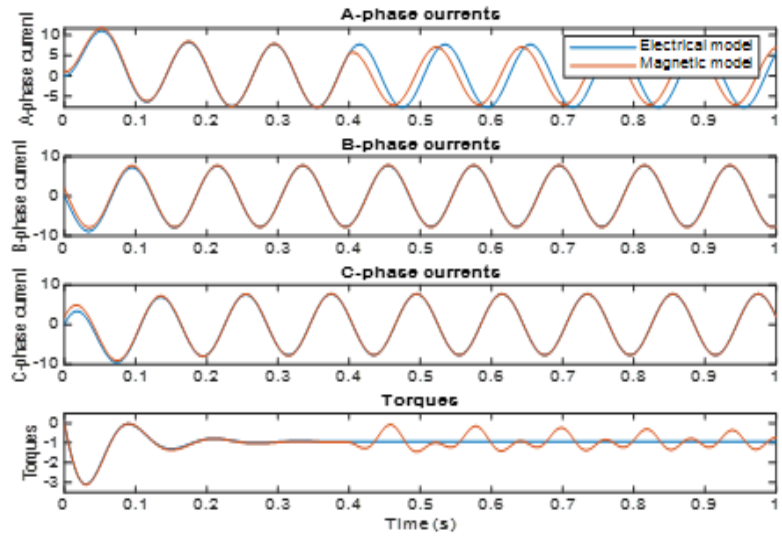

Figure 9 a: Stator currents, torque
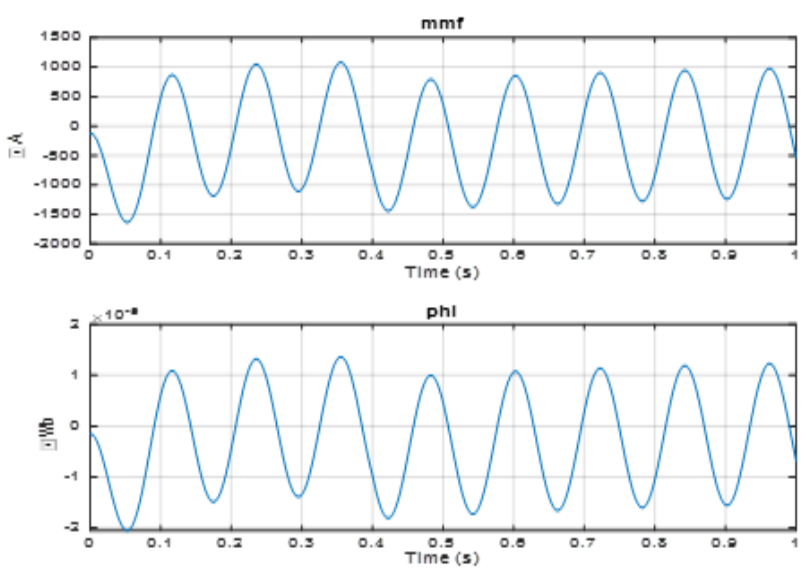

Fig. 9 b: Distribution of mmf \& flux
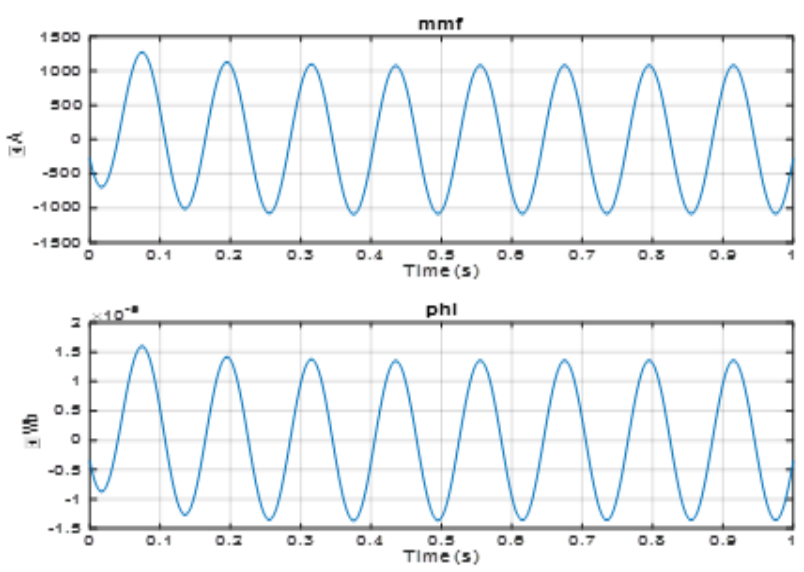

Figure 10: Distribution of mmf and flux
5.4 Isolations (Air gap) between windings fault in 'Tooth 1' of phase ' $A$ '

Use of motors over the years may result air-gap between windings of phases causing isolation of windings. This fault of winding is applied at $\mathrm{T}=0.4 \mathrm{sec}$ in 'Tooth 1 'of phase ' $\mathrm{A}$ '. The simulated waveforms for stator currents and torque after occurrence of fault is shown in Figure 11a and that of 'mmf' and 'flux' is shown in Figure 11 b, normal flux is seen in T4T5 Tooth(healthy) during same time and is shown in Figure 12.

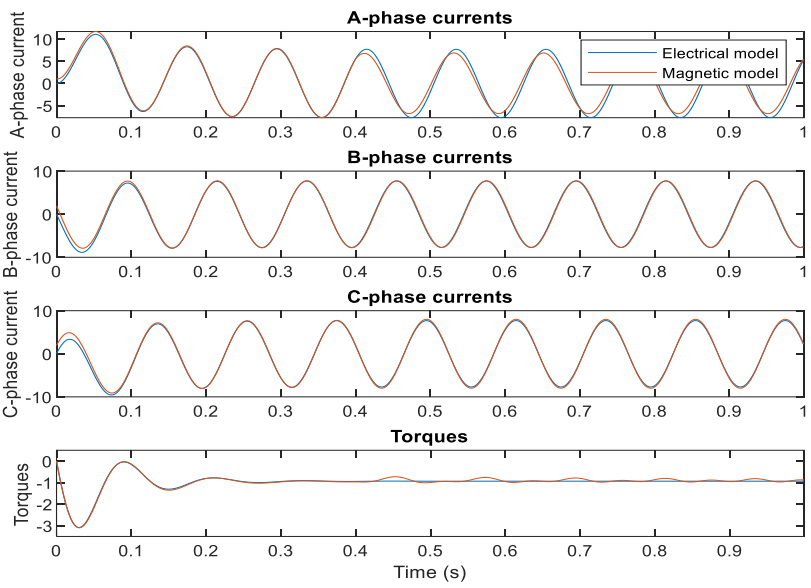

Fig. 11 a: Stator currents, torque
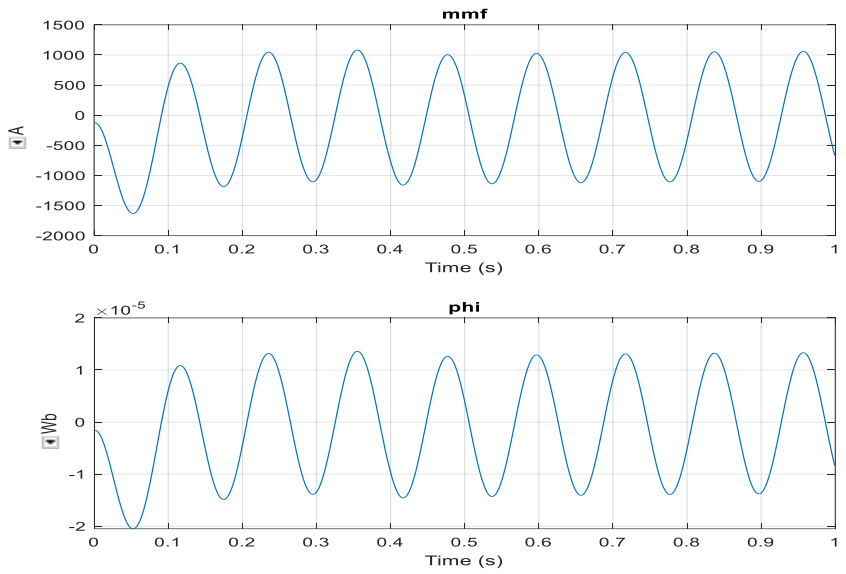

Figure 11 b: Distribution of mmf \& flux
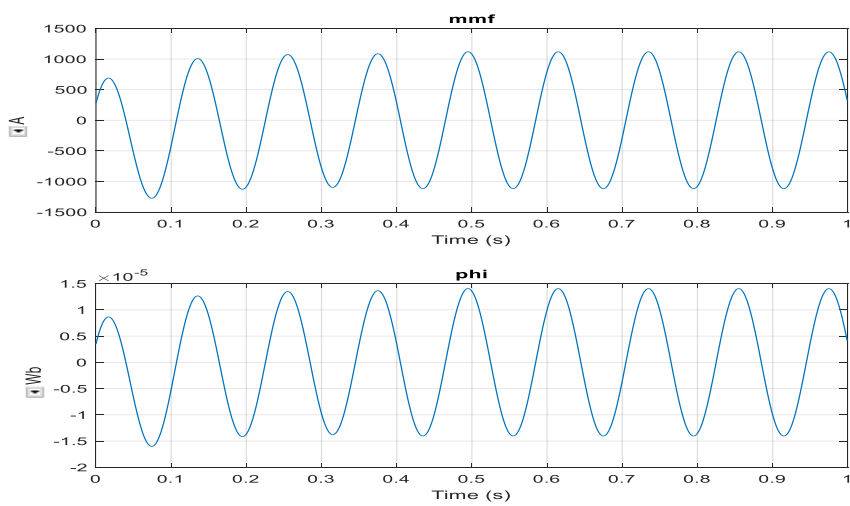

Figure 12: Distribution of $\mathrm{mmf}$ and flux 


\section{CONCLUSIONS}

Paper discussed analysis that fault currents caused by winding failures can be many times the rated current. If nothing is done, the winding failures may spread quickly and can cause a major fault. The results show that by measuring stator ripple current, it is possible to detect winding open circuits and short circuits. Proposed detection method is a simple technique and will be equally applicable for machines of different ratings. The detection system for inverter-driven machines operating in current control can easily be implemented into the motor controller without the need for additional sensors.

Whilst this method of detection of winding failures is presented for fault tolerant permanent magnet synchronous machines. It will also work for other types of machines, such as switch reluctance motors and induction motors, which have winding failures that are equally severe as in PMSM. It has been demonstrated that when a winding failure are identified, PMSM using per unit reactance can be applied to the faulted phase. If the machine has little mutual coupling between phases it can continue to operate.

\section{ACKNOWLEDGMENTS}

Äuthors would like to thank Government College of Engineering, Aurangabad, (M.S.), India, for support and research facility.

\section{REFERENCES}

[1] Tousizadeh M.; Che, H. S.; Selvaraj J.;Rahim; Ooi ,N. A..Faulttolerant field-oriented control of three-phase induction motor based on unified feed- forward method. IEEE Transactions on Power Electronics, 2018; vol. 34, no. 8, pp. 7172-7183.

[2] Gan C, Y; Chen, R; Qu, Z. Yu, Kong W., and Y. Hu. An overview of fault-diagnosis and fault-tolerance techniques for switched reluctance machine systems IEEE Access 2019; vol. 7, pp. $174822-174838$.

[3] Tian B.; Mirzaeva , An G.; Q.-T., L. Sun, and D. Se Menov. Fault-tolerant control of a five-phase permanent magnet synchronous motor for industry applications; IEEE Transactions on Industry Applications, 2018; vol. 54, no. 4, pp. 3943-3952.

[4] Yang, H.;Q.-L. Han; X. Ge, L. Ding; Y. Xu; B. Jiang; D. Zhou. Fault tolerant cooperative control of multi-agent systems: A survey of trends and methodologies. IEEE Transactions on Industrial Informatics, 2019

[5] S. Yin; B. Xiao; S. X. Ding; D. Zhou. A review on recent development of spacecraft attitude fault tolerant control system IEEE Transactions on Indus- trial Electronics, 2016; vol. 63, no. 5, pp. 3311-3320..

[6] E. Dijoux ; N. Y. Steiner; M. Benne; M.-C. P'era, , B. G. $\mathrm{P}^{\prime}$ erez. A review of fault tolerant control strategies applied to proton exchange membrane fuel cell systems. Journal of Power Sources; 2017, vol. 359, pp. 119-133.

[7] M. Bourogaoui; H. B. A. Sethom; I. S. Belkhodja. Speed/position sensor fault tolerant control in adjustable speed drives-a review, ISA transactions, 2016; vol. 64, pp. 269-284.

[8] Jlassi; J. O. Estima; S. K. El Khi; , N. M. Bellaa; A. J. M.
Cardoso. A robust observer-based method forIGBTs and current sensors fault diagnosis in voltage-source inverters of pmsm drives IEEE Transactions on Industry Applications;2016; vol. 53, no. 3, pp. 2894-2905.

[9] M. A. Mazzoletti; G. R. Bossio; C. H. De Angelo; D. R. Espinoza-Trejo. A model-based strategy for interturn shortcircuit fault diagnosis in pmsm. IEEE Transactions on Industrial Electronics, 2017; vol. 64, no. 9, pp. 7218-7228.

[10] Z. Yang, Y. Chai, H. Yin, and S. Tao. Lpv model based sensor fault diagnosis and isolation for permanent magnet synchronous generator in wind energy conversion systems. Applied Sciences.2018; vol. 8, no. 10, p. 1816-1826.

[11] R. Liu; B. Yang; E. Zio; X. Chen. Artificial intelligence for fault diagnosis of rotating machinery: A review Mechanical Systems and Signal Processing. 2018; vol. 108, pp. 33-47.

[12] I.H. Kao; W. J. Wang; Y.-H. Lai, J -W. Perng Analysis of permanent magnet synchronous motor fault diagnosis based on learning IEEE Transactions on Instrumentation and Measurement 2018; vol. 68, no. 2, pp. 310-324.

[13] L. Chen; Z. Zhang ; J. Cao, X. Wang. A novel method of combining nonlinear frequency spectrum and deep learning for complex system fault diagnosis. Measurement. 2020; vol. 151, pp. 107-115.

[14] S. Wang; J. Bao; S. Li; H. Yan; T. Tang; D. Tang. Research on interturn short circuit fault identification method of pmsm based on deep learning. in 22nd International Conference on Electrical Machines and Systems (ICEMS). IEEE, 2019, pp. 1-4.

[15] H. Yan; Y. Xu; F. Cai; H. Zhang; W. Zhao; C. Gerada. PWM VSI fault diagnosis for a pmsm drive based on the fuzzy logic approach. IEEE Transac tions on Power Electronics; 2018; vol. 34, no. 1, pp. 759-768..

[16] N. Misron; M. A. M. Radzi. Fault detection of broken rotor bar in ls-pmsm using random forests Measurement 2018; vol. 116, pp. 273-280.

[17] S. Liang; Y. Chen; H. Liang. X. Li Sparse rep- resentation and svm diagnosis method for inter-turn short-circuit fault in pmsm. Applied Science,2019; vol. 9, no. 2, p. 224-234.

[18] M. Armin; P. N. Roy; S. K. Das. A survey on modelling and compensation for hysteresis in high speed nano positioning of afms: Observation and future recommendation. International Journal of Automation and Computing; 2020; vol. 17, pp. 1-23.

[19] S. K. Kommuri; M. Defoort ; H. R. Karimi; K. C. Veluvolu. A robust observer-based sensor fault-tolerant control for pmsm in electric vehicles. IEEE Transactions on Industrial Electronics.2016; vol. 63, no. 12, pp. 7671-7681.

\section{Author's Information}

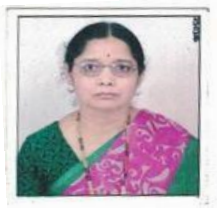

Sandhya Kulkarni: She is presently working as an Associate Professor in the Department of Electrical Engineering at the Govt. College of Engineering in Aurangabad, Maharashtra, India, where she is also pursuing research. Her research interests include fault tolerant control and drive control. 


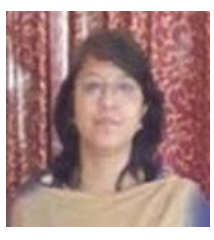

Dr. Archana Thosar: She received his BE in Electrical Engineering from Shivaji University in 1992, ME in Electrical Engineering with Control System as specialization from Shivaji University Kolhapur in 1997 and $\mathrm{PhD}$ in Electrical Engineering from IIT Kharagpur in 2009. Presently working as Professor in Electrical Engineering in College of Engineering, Pune. Her research interests include Fault tolerant Control, Control System, Renewable energy, Energy Minimizing Control.

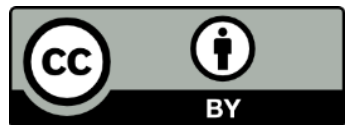

(C) 2021 by the Sandhya Kulkarni and Dr. Archana Thosar. Submitted for possible open access publication under the terms and conditions of the Creative Commons Attribution (CC BY) license (http://creativecommons.org/licenses/by/4.0/). 